\title{
Study of bronchial hyper-reactivity in patients with allergic rhinitis in an urban indian setup
}

\author{
Priti Meshram*, Dattatraya Birajdar, Nagsen Ramraje \\ From 3rd WAO International Scientific Conference (WISC) 2014 \\ Rio de Janeiro, Brazil. 6-9 December 2014
}

\section{Background}

The concept of Atopic march was developed to study the progress of Atopic Dermatitis to Allergic Rhinitis to Asthma. Epidemiologic studies have constantly demonstrated strong associations between Rhinitis and Asthma. Bronchial hyper-reactivity is an important component in the definition of Asthma. Many patients with Allergic Rhinitis have lower Airway hyperreactivity or bronchial hyper-responsiveness without obstructive ventilatory defect on PFT indicating that such patients may have a risk of developing Asthma. Most of these studies have been conducted in the Western countries. Our study aimed to detect the presence of Bronchial hyper-reactivity in patients with Allergic Rhinitis with normal lung function tests in our set up.

\section{Methods}

In our study, 40 patients of Allergic Rhinitis with normal PFT were screened by Bronchial Challenge Tests (BCT) for the presence of Bronchial hyperreactivity after obtaining required ethical clearance from the Institutional Ethics Committee.

\section{Observations}

Allergic Rhinitis, especially without any respiratory presentation was commonly seen in the younger age group. The study population comprised of predominantly male patients. Majority of the patients in the study had Mild Allergic Rhinitis. More than half the study population had Bronchial Hyper-reactivity. Of these, majority had severe Bronchial Hyper-reactivity. It was found that as the duration of symptoms increased in years, the concentration of Histamine at which the BCT was positive decreased and the correlation was found to be significant. No significant correlation was found between

Grant Government Medical College, India

C 2015 Meshram et al: licensee BioMed Central Ltd. This is an Open Access article distributed under the terms of the Creative Commons Attribution License (http://creativecommons.org/licenses/by/4.0), which permits unrestricted use, distribution, and reproduction in any medium, provided the original work is properly cited. The Creative Commons Public Domain Dedication waiver (http://creativecommons.org/publicdomain/zero/1.0/) applies to the data made available in this article, unless otherwise stated. 